\title{
Women's Sexual Health During the Pandemic of COVID-19: Declines in Sexual Function and Sexual Pleasure
}

\author{
Leonor de Oliveira $^{1} \cdot$ Joana Carvalho $^{1}$ (C) \\ Accepted: 10 June 2021 / Published online: 3 July 2021 \\ (C) The Author(s), under exclusive licence to Springer Science+Business Media, LLC, part of Springer Nature 2021
}

\begin{abstract}
Purpose of the Review The World Health Association declared COVID-19 a pandemic more than 1 year ago. We conducted a systematic review of the literature on the topic of women's sexual health during the pandemic, with a focus on sexual function and sexual pleasure. Our aim is to describe current findings and to discuss implications for women's sexual health during this period.

Recent Findings Thirty-four articles, from 18 countries, were identified. These studies addressed topics ranging from individual aspects, such as cognitive, emotional, and personality factors affecting sexuality during the pandemic, to contextual factors, including relationship, childrearing, and employment status in this period.

Summary Research identified a deterioration of women's sexual function across countries, with an emphasis on sexual desire. Most studies found decreases in the frequency of sexual intercourse during the pandemic and increases in solitary sexual behavior. Many women also experienced declines in sexual satisfaction and relationship satisfaction. Findings suggested that gender inequalities contributed to lower indices of sexual function and satisfaction, and might have exacerbated the pleasure gap between men and women.
\end{abstract}

Keywords Sexual health $\cdot$ Sexual function $\cdot$ Sexual pleasure $\cdot$ Women $\cdot$ Gender inequality $\cdot$ COVID-19

The World Health Association considered the outbreak of COVID-19 the greatest health threat of the past century [1]. Because virus transmission occurs via close human contact, social distancing became indispensable to avoid spreading the virus. Many countries endorsed lockdown measures, which included but were not limited to contact bans, curfews, and travel restrictions, leading to a global economic crisis [2] and to mental health deterioration among the general population $[3,4]$ and in medical care personnel [5].

Recommendations related to sexual activity were issued by the New York City Health Department to decrease COVID-19 transmission rates; masturbation was considered the safest sexual practice, followed by having sex with a cohabitating

This article is part of the Topical Collection on Female Sexual Dysfunction and Disorders

Joana Carvalho jcarvalho@fpce.up.pt

1 Center for Psychology at University of Porto, Faculty of Psychology and Educational Sciences, University of Porto, R. Alfredo Allen, 4200-135 Porto, Portugal partner [6]. Consequently, numerous individuals were forced to repress or to reformulate sexual life [7]. Debate in the scientific community prompted as to whether confinement would lead to increases or decreases in sexual activity [8]. Similar debates were taking place in the media. In an overview of media narratives on this topic, Döring [2] found speculations about coronavirus baby booms, divorces due to declines in sex, the obliteration of casual sex, and increased use of telephonic and online sex. The media also predicted higher frequency of masturbatory behavior, sex toy use, pornography use, and the emergence of coronavirus porn as a new genre of pornography.

Among the many societal consequences of the COVID-19 outbreak, several deleterious effects were expected to have a particular impact on women's sexual rights and sexual health [9]. Sexual health refers to a state of physical, emotional, mental, and social well-being in relation to sexuality, which requires respect for everyone's sexual rights and the possibility of pleasurable sexual activity [10]. Although sexual rights need to be safeguarded during crisis, sexual well-being is often neglected at the face of more significant immediate concerns [11]. Because sexual wellness may be considered 
nonessential, sexual medicine services might be reduced along with maternal and reproduction health services, affecting women disproportionately $[12,13]$. In addition, preexisting inequalities affecting homelife, work [14, 15], and sexual pleasure $[16,17]$, as well as higher vulnerability to affective disorders [18-20], and to sexual dysfunction [21, 22], could be contributing to decreased sexual health among women during this period. Notably, sexual problems manifest in the context of overlapping systems of oppression that besides gender also intersect with aspects such as race, ethnicity, and socioeconomic status [23]. Therefore, some women may face an additional strain on their sexual rights during the COVID-19 pandemic, including those from developing countries [13, 24], and from marginalized groups [25].

More than 1 year after the World Health Association declared COVID-19 a pandemic, we review up to date research on the topic of women's sexual health during this period. Our aim is to provide an overview of data on this matter and to discuss its intersections with sexual pleasure as a fundamental right. Considering previous data, we are expecting to find mainly literature describing challenges to women's sexual health during this pandemic and limited data on their enhanced sexual pleasure.

\section{Methods}

A systematic search was conducted in EBSCO, Scopus, Web of Science, and PubMed databases for papers published until early April 2021 using an exhaustive list of key terms. These were "sexual health" AND "covid"; "sexual function" OR "sexual dysfunction" AND "covid"; "sexual desire" OR "sexual excitation" OR "sexual pain" OR "orgasm" AND "covid; and "sexual pleasure" OR "sexual satisfaction" AND "covid". In this review, we only included peer-reviewed empirical articles concerning the topic of interest written in English, Portuguese, or Spanish languages. Studies that recruited only men or adolescents were excluded. References were cross checked to identify additional papers.

\section{Results}

This review includes 34 articles from 18 countries related to the impact of COVID-19 on women's sexual health. Overall, findings revealed that women's sexual function decreased during this period, with most studies emphasizing negative effects on sexual desire. Numerous studies found decreases in the frequency of sexual intercourse during the pandemic, while finding increases in solitary sexual behavior. In addition, many women also experienced declines in sexual satisfaction and relationship satisfaction. The large majority of these studies used the Female Sexual Function Index (FSFI) [26].

This review suggests that there are vulnerability factors affecting sexuality during the pandemic. These include individual aspects (psychological adjustment, and personality), interpersonal factors (relationship factors, cohabitation status, and childrearing), and societal factors (work type and employment status, living area, and gender inequalities). We found several relationships between variables which have been previously associated in the literature (e.g., sexual satisfaction and sexual function, dyadic adjustment and sexual satisfaction), and might not be specific to the pandemic. In contrast, findings on vulnerability factors, including those related with cohabitation, childrearing, and work, are very heterogeneous. See Table 1 for an overview of results as well as studies' characteristics.

\section{Changes in Sexual Function and Sexual Behavior}

In a qualitative study with health professionals, clinical sexologists perceived that sexual problems and sexual dysfunction were aggravated by the context of COVID-19 [29]. Several studies corroborate those perceptions, as findings identified decreases in women's scores in sexual function [30-34] and sexual satisfaction during the pandemic, compared to prepandemic [27, 32, 34-37]. Even so, one study with patients with epilepsy did not find significant changes [38]. Furthermore, declines in sexual function during the pandemic were associated with lower quality of life in women [39].

Sexual desire seems to have been particularly affected, showing significant decreases during this period [36, 40, 41], although some studies have found the opposite [27, 35, 42]. Still, two of the three studies that found increases in sexual desire during the pandemic did not use validated questionnaires to assess sexual function [27, 35], which may explain these contradictory findings.

Most studies found decreases in the frequency of sexual intercourse as well [30-33, 37, 40, 41, 43-47], and one study verified that women were two times more likely than men to use sexual avoidance behaviors [30]. However, there is at least one study that did not find any changes compared to prepandemic levels [35], and one study finding significant increases in the average weekly frequency of sexual intercourse during the pandemic compared with the 6-12 months prior (2.4 vs $1.9 ; p=0.001$ ) [42]. Conversely, the large majority of the studies found increases in masturbation behavior and viewing pornography during the pandemic $[27,30,35,40$, 44, 47]. Specifically, Zattoni, Gül [48], in an analysis of Google Trends® from January 9, 2020 to May 25, 2020, found an increased interest in pornography and coronavirusthemed pornography after the outbreak of COVID-19 in the countries under lockdown (refer to Table 1 for details). Together, findings point at a clear reduction of sexual 


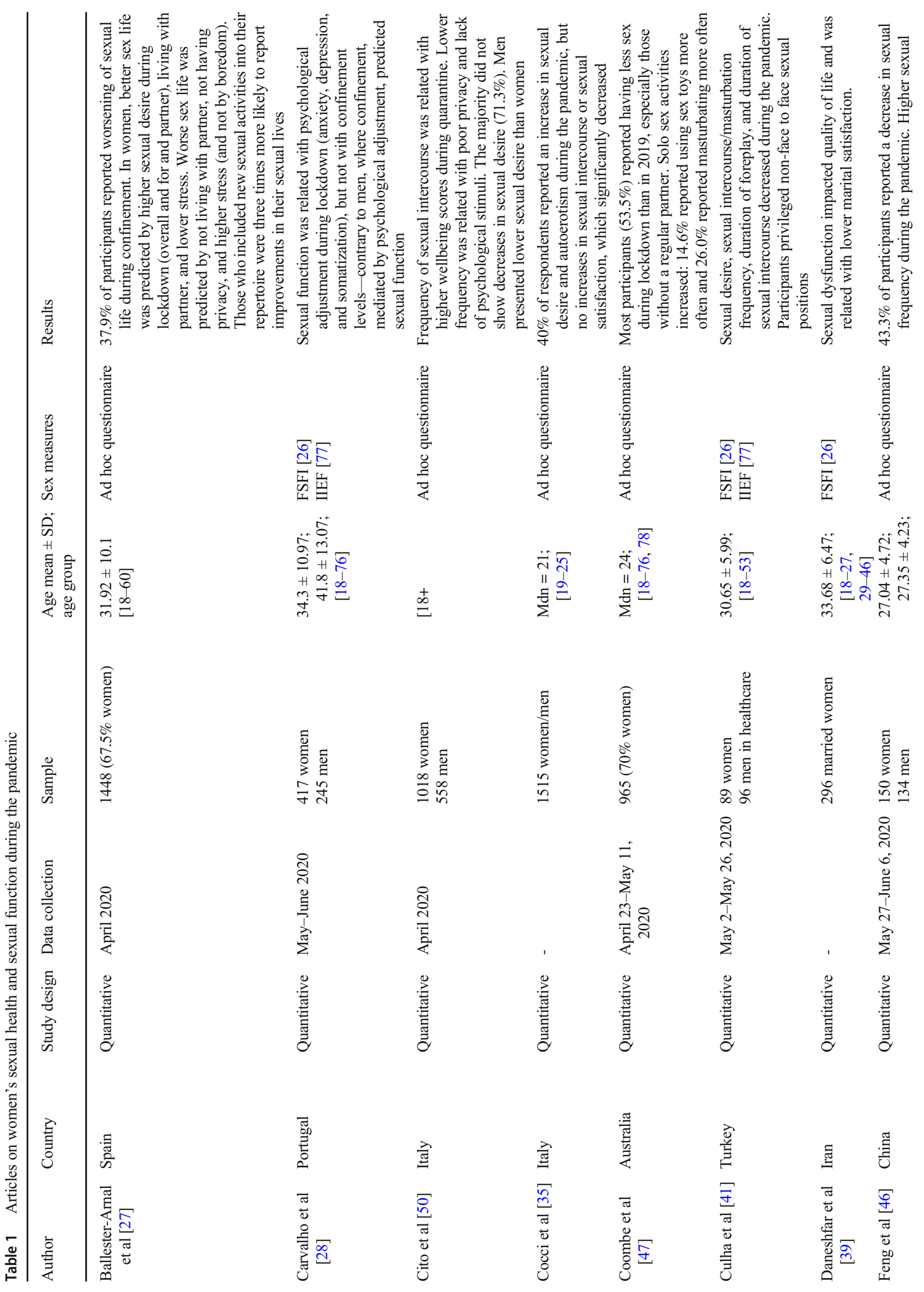




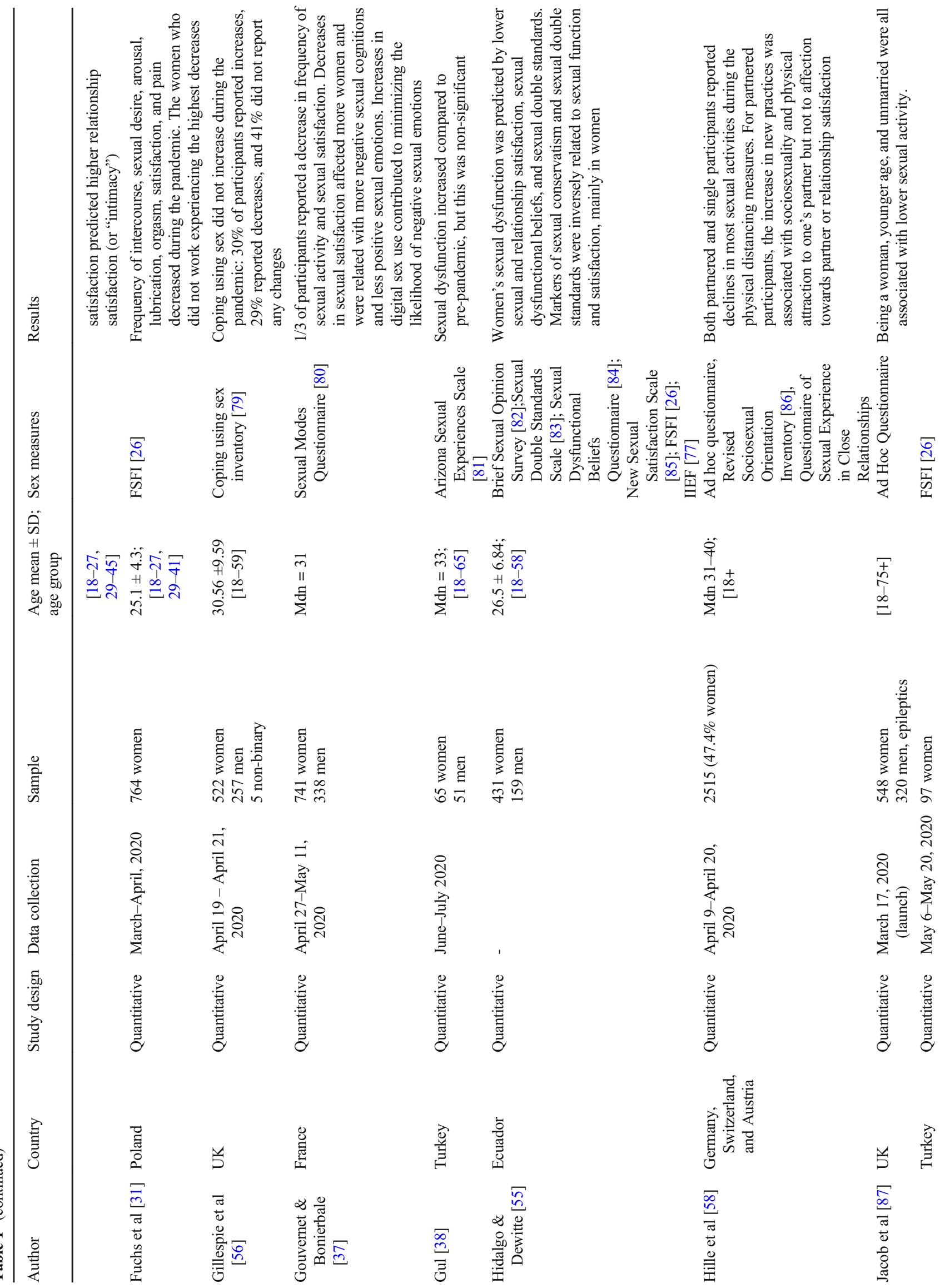




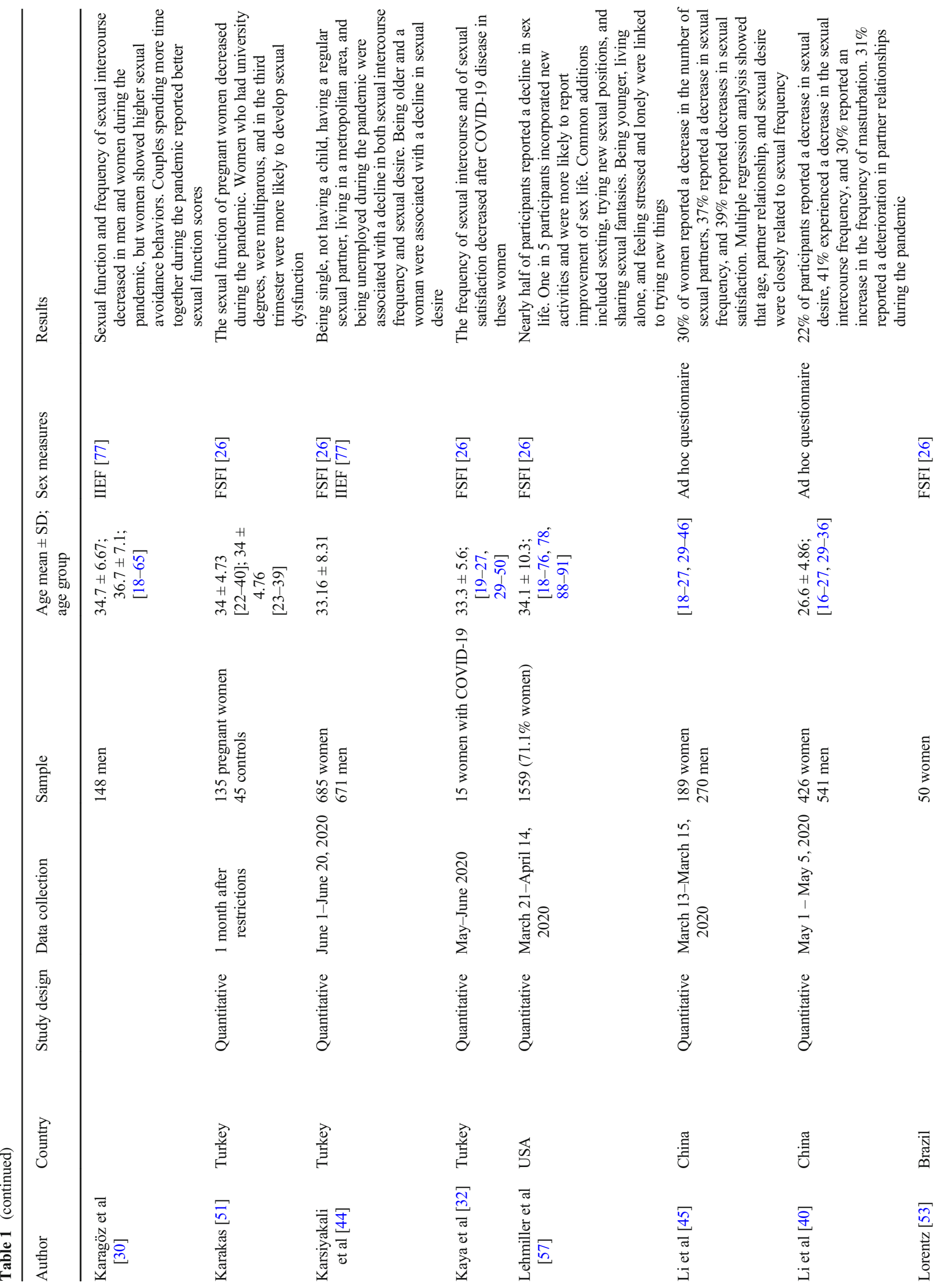




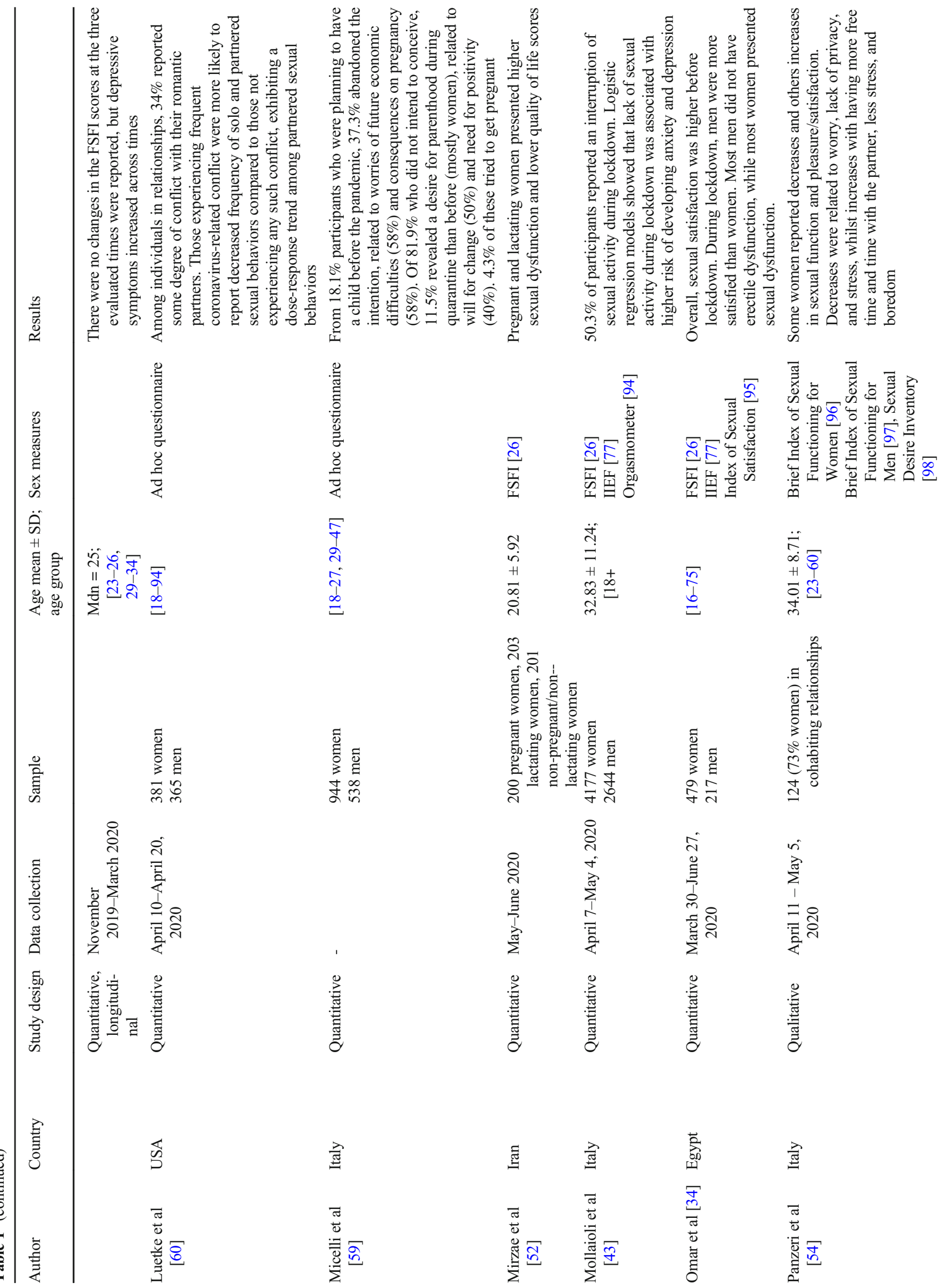




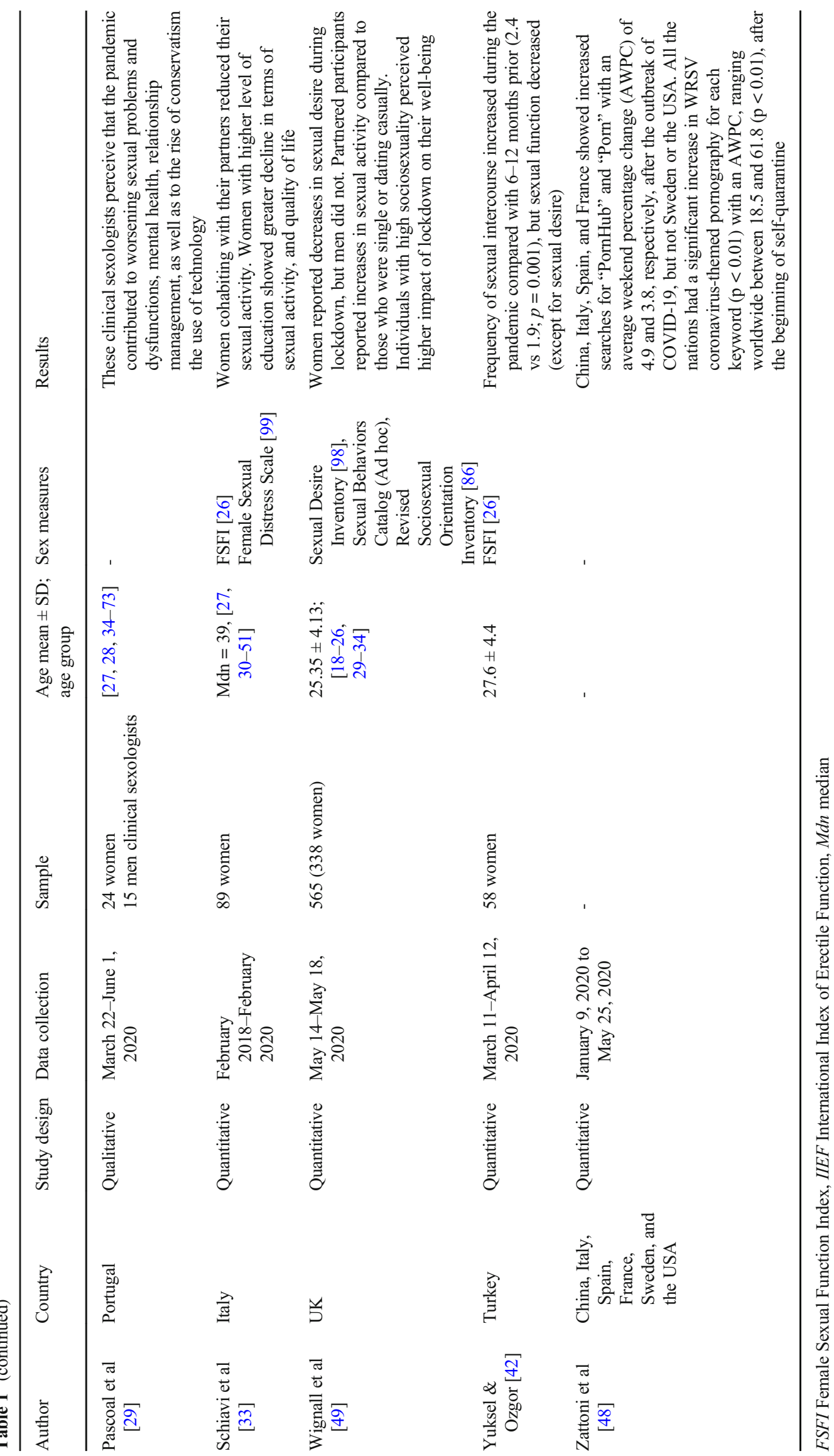


intercourse, while finding increases in masturbation behavior in women during the pandemic.

Furthermore, research found overall decreases in the number of sexual partners, risky sexual behavior [40, 45], and in contraception use [42] (refer to Table 1 for details). In the study of $\mathrm{Li}, \mathrm{Li}$ [45], there were also $30 \%$ of women reported having less sexual partners, and only 5 individuals of a total of 459 (not specified whether they were men or women) reported increased sexual risk. However, in the same study, $18 \%$ of women indicated that they were inclined to increase the number of sexual partners and risky sexual behaviors once the outbreak ended.

\section{Contribution of Individual Factors}

Gender, age, and educational attainment may be associated with sexual function and sexual wellness in the context of the pandemic. Several studies indicated that women experienced more sexual functioning issues [34, 36, 44, 49], higher sexual distress [34], and lower sexual satisfaction [27, 34, 37] during the pandemic compared to men. However, some studies found that men were experiencing lower sexual desire $[27,50]$ and more sexual dysfunction [41] compared to women. Pregnant women may be more severely affected in terms of sexual function $[51,52]$ and, possibly, puerperal women too, although it is unclear from this study if the decline in sexual function was pandemic related [53]. In addition, being older [36, 44, 45] and having a higher education $[33,51]$ were linked to declines in sexual functioning and sexual activity.

Declines in women's sexual function and sexual satisfaction during the pandemic were associated with lower psychological adjustment [28], higher anxiety and depression [30], additional worry and stress [54], more negative sexual cognitions and less positive sexual emotions [37], and with sexual conservatism and sexual double standards [55]. Increases in sexual function and frequency were related with higher boredom, lower stress [27, 54], lower anxiety, and with lower depression [43]. Some individuals seem to have specifically used sex to cope during lockdown [56].

Some studies which found declines in sex life, i.e. sexual activity and sexual function, also found that sex life improved for some individuals $[27,57,58]$. Improvements were related with higher overall sexual desire and sexual desire for the partner, and with incorporating new sexual activities, such as sexting, new sexual positions, and sharing sexual fantasies $[27,57]$. New practices, on the other hand, were associated with sociosexuality and physical attraction to one's partner, but not with affection towards partner or relationship satisfaction [58]. At the same time, individuals with high sociosexuality perceived higher impact of lockdown on their wellbeing [49].

\section{Contributions from Interpersonal and Societal Factors}

Living situation, including partner availability and the presence of children at home, was associated with changes in sexual function during the pandemic, although results are somewhat mixed. On one hand, being single and living alone accounted for declines in sexual function and sexual activity during the pandemic [31, 44, 49], but so did having a regular partner [44] and living with one's partner [36]. Studies with young women found that the ones living with their parents were the ones presenting the highest decreases in FSFI scores $[31,33]$. In the study of Fuchs, Matonóg [31], the smallest differences between pre-pandemic and pandemic referred to the women living with their partner with no children. On the other hand, declines in sexual life were related with poor privacy and lack of psychological stimuli $[27,50,54]$, while improvements were related with having more free time and spending more time with the partner [30,54]. In line with these findings, other research found that having children contributed to decreased sexual function in women [31,36], but so did not having children [44]. Some women revealed having more desire for parenthood during quarantine than before due to need for change and positivity, but many dropped intentions to conceive [59]. In conclusion, both feeling lonely at home and having a home that feels too crowded for privacy have impacted sexual function.

Studies also show that relationship satisfaction was correlated with sexual satisfaction $[46,55]$ and inversely correlated with sexual dysfunction in women during this period [39, 43]. As for relationship conflict, this was related with having less sexual activity [40], and corona-related conflict in particular accounted for lower frequency of both solo and partnered sexual behaviors [60].

In addition, shifts in work - from employment to unemployment, from working in an office to working from home - seem to be associated with changes in sexual function and sexual activity. Being unemployed seems to be responsible for declines in sexual function and sexual activity [31,44], yet challenges stemming from shifts at work also seemed to have an impact. Some studies have identified bigger declines in sexual function on those who work from home [31], while others state the opposite, i.e., that essential workers were affected with bigger declines in sexual function [33]. In line with this, a study with healthcare workers in Italy showed that a statistically significant higher proportion of healthcare workers had low sexual desire compared to their acquaintances who did not work at the hospital [36].

Finally, living in a metropolitan area during the pandemic outbreak was associated with declines in sexual desire and reduced sexual activity, possibly because these areas were under severer restrictions [44]. 


\section{Discussion}

This review suggested that women's sexual health and wellbeing might have been disproportionately affected during the COVID-19 pandemic throughout 2020, as predicted. According to our findings, women experienced more sexual problems than men, including low sexual desire and low sexual satisfaction [e.g., 32, 35, 48]. Most studies found decreases in the frequency of sexual intercourse during the pandemic, but also found increases in solitary sexual behavior [e.g., 28, $39,43]$, which may imply that the declines in sexual desire were affecting mostly partner relationships. While the fact that there was an increase in masturbation and pornography use fits the media narratives described by Döring [2], the speculated "coronavirus babyboom" seems unlikely considering the drops in sexual intercourse, and in intention to conceive during 2020 [59]. This does not mean, however, that this trend is carried on in 2021. As for the prevision of the rise of the new genre of coronavirus themed pornography, this proved to be correct [48].

Research found negative relationships between some individual aspects and sexual function, such as age, level of stress, anxiety, and depression, and negative sexual cognitions and emotions $[28,30,37,43,55]$. These do not appear to be pandemic specific, considering that previous research has established that anxiety and depression and their treatments contribute to higher rates of sexual dysfunction [61, 62]. As well, dysfunctional sexual beliefs and emotions were also proven to negatively affect women's sexual health $[63,64]$. Nevertheless, the fact is that during this period, many people experienced higher levels of stress, and this seems to have put them at greater risk for sexual dysfunction.

This review also found that higher boredom was related with increased sexual activity and sexual function [27, 54] and that some individuals used sex to cope during lockdown [56]. Some researchers suggest that sex can be a coping mechanism for managing boredom, which has been linked to masturbation and hypersexuality [65, 66]. Boredom was identified as an important stressor for those in isolation during the pandemic [67]. Possibly, for some individuals feeling bored due to isolation, sex was welcomed as a positive distraction. As for individuals who score highly on measures of sociosexuality, who were unable to pursue sex on their terms, including casual sex, they perceived higher impact of lockdown on their well-being [49]. On the other hand, sociosexuality and physical attraction to the partner were associated with introducing new sexual practices during this period [58]. In fact, improvements in sex life during the pandemic were related with higher sexual desire overall and for partner, and with incorporating new sexual activities [27, 57]. Pre-pandemic studies found that sexual novelty was inversely correlated with sexual boredom [68] and that the inability or unwillingness to engage in novel sexual behavior was positively correlated with sexual boredom [69]. In a recent qualitative study with a large community sample, participants described sexual boredom as the sexual monotony and/or lack of sexual interest that is often linked to the interpersonal aspects of long-term sexual relationships [70]. During COVID-19, many couples changed their lifestyles to comply with restrictions and were forced to face monotony. It seems as if this did not necessarily send them to sexual boredom, as some seemed to have reacted to feelings of boredom by introducing new sexual activities and enhancing sexual desire. Nevertheless, some individuals might not have had the tools to fight pandemic induced boredom and sexual boredom, and this could have affected their sexual function. Yet, that assumption was not investigated.

Relationship factors are known to affect sexual health [71-73]. However, the extent to which the pandemic impacted relationship quality is unclear. This is especially relevant for women in sexual violent relationships, who became more vulnerable and isolated during this pandemic [2,9]. Yet, this review did not focus on sexual violence. Additionally, this review found that women living with their partners and having more free time and better opportunities for partnered quality time [30,54], or women having higher relationship satisfaction, felt more sexually satisfied $[46,55]$ and had less sexual dysfunction [39, 43]. On the other hand, those experiencing conflict in their relationship had sex less often [40,60]. Also, negative changes in relationship satisfaction during COVID19 were related with having dyadic conflict, poor coping [74], and with having children at home for school, irrespectively of work status [75]. Although the current review did not include studies examining same-sex couples, other research has identified that in the pandemic context, being a person of color and having higher internalized homophobia exacerbated the pandemic's negative effects on relationship satisfaction [76]. Thus, it seems highly relevant that these populations are investigated.

Working was one of the life areas where individuals faced more changes. Many people had to adjust their routines to work from home, while essential workers had to manage additional risk at their workplaces. These shifts impacted on individuals' sexual health $[31,33]$, particularly in subjects who were, or who became, unemployed [31, 44], or in healthcare workers [36, 41], possibly due to increased stress levels. Conversely, those working from home also saw declines in sexual health [31], specifically those who struggled with anxiety, depression, and somatization, although for women, this was not related with their level of confinement [28].

Some authors $[41,44,51]$ speculated that the declines in sexual function and sexual activity were a result of the level of education or information on the virus of COVID-19. That is, well-informed or educated individuals were more afraid and/ 
or compliant with social distancing, experiencing higher dysfunction and less sexual activity. Even though we might consider that access to information may have privileged solitary sexual behavior at some level, we are not sure whether it was a major factor determining sexual function. In reality, research shows that interventions aiming at sexual education favor women's sexual function and pleasure $[78,88]$. In addition to possible spillover effects, the declines in the sexual function of women with more access to education or information seem to us a more likely result of lack of parity between men and women. There were several authors who alerted that the advent of teleworking would exacerbate gender inequalities [9, $89,90]$. This review suggests that these inequalities, including childrearing, contributed to lower indexes of sexual function and satisfaction, which in turn provide evidence of pleasure inequality. Because some women may struggle with negotiating sexual pleasure and tend to favor men's sexual pleasure $[91,92]$, it is possible that during this pandemic, these women engaged in sex in the absence of sexual desire or in the presence of sexual pain. This is likely to have resulted in pleasureless sex and, consequently, to even have lowered levels of sexual function. Although not many studies used measures of sexual pleasure, and rather of sexual satisfaction, the findings of this review leave one to guess that the pandemic may have had stretched the pleasure gap between men and women.

\section{Implications}

Because pleasure is an important dimension of sexual health [93], equality in sexual pleasure is not just relevant, it is essential. The fact that women's sexual pleasure might have been particularly affected due to COVID-19 related downfalls, it is a symptom of gender inequality in sexuality. Although it seems impossible to determine at this stage if there will be long-term negative effects of the pandemic in women's sexual health, this matter should be further investigated as the effects of pandemic are still felt globally. An important note on this topic is that studies were mainly focused on women from western cultures, masking the specific challenges of women from developing countries, who have probably faced additional difficulties. In addition, there is a big gap in research regarding sexual minorities, as we did not find any studies focused on LGBTQIA+ or non-monogamous populations. Research on COVID-19-related sexual problems also raises questions on whether sexual dysfunctions should be diagnosed when they are likely caused by identifiable external factors. The main opportunity stemming from the ongoing pandemic might be that the current lack of resources for meeting with the community may lead to the improvement and dissemination of e-Health tools as applied to the context of sexual health and pleasure, and finally reach a wider population.
Author contribution In this work, the background idea was provided by JC, i.e., intersecting the topic of women's sexual health during COVID19 with the realm of sexual rights. LO performed the search (revised by JC) and drafted the manuscript. JC critically revised it, building a bridge between findings and a societal interpretation of data.

\section{References}

1. World Health Association. A year without precedent: WHO's COVID-19 response. 2021 [cited 2021 March 2]; Available from: https://www.who.int/news-room/spotlight/a-year-withoutprecedent-who-s-covid-19-response.

2. Döring N. How Is the COVID-19 Pandemic affecting our sexualities? An overview of the current media narratives and research hypotheses. Arch Sex Behav. 2020;49(8):2765-78.

3. Rossi R, et al. COVID-19 Pandemic and lockdown measures impact on mental health among the general population in Italy. Frontiers in Psychiatry. 2020;11(790).

4. López-Bueno R, et al. Association between current physical activity and current perceived anxiety and mood in the initial phase of COVID-19 confinement. Frontiers in Psychiatry. 2020;11(729).

5. Zhang Y, et al. Factors influencing mental health of medical workers during the COVID-19 outbreak. Front Public Health. 2020;8(491).

6. NYC Health Department Safer Sex and COVID-19. 2020.

7. Maretti C, et al. COVID-19 pandemic and its implications on sexual life: Recommendations from the Italian Society of Andrology. Archivio italiano di urologia, andrologia : organo ufficiale. Societa italiana di ecografia urologica e nefrologica. 2020;92. https://doi.org/10.4081/aiua.2020.2.73

8. Ibarra FP, Mehrad M, Mauro MD, Godoy MFP, Cruz EG, Nilforoushzadeh MA, et al. Impact of the COVID-19 pandemic on the sexual behavior of the population. The vision of the east and the west. Int Braz J Urol. 2020;46(suppl.1):104-12.

9. Carvalho J, Pascoal PM. Challenges in the practice of sexual medicine in the time of COVID-19 in Portugal. J Sex Med. 2020;17(7): $1212-5$.

10. World Health Association. International statistical classification of diseases and related health problems, World Health Association: Geneva. Switzerland. 2018

11. Banerjee D, Rao T. Sexuality, sexual well being, and intimacy during COVID-19 pandemic: an advocacy perspective. Indian J Psychiatry. 2020;62(4):418-26.

12. Shindel AW, Rowen TS. Challenges in the practice of sexual medicine in the time of COVID-19 in the United States. J Sex Med. 2020;17(7):1216-9.

13. Hussein J. COVID-19: What implications for sexual and reproductive health and rights globally? Sexual and Reproductive Health Matters. 2020;28(1):1746065.

14. Padavic I, Ely RJ, Reid EM. Explaining the persistence of gender inequality: the work-family narrative as a social defense against the 24/7 work culture. Adm Sci Q. 2019;65(1):61-111.

15. Dalingwater, L., Neo-liberalism and gender inequality in the workplace in Britain. French Journal of British Studies, 2018. 23(XXIII-1).

16. Mahar EA, Mintz LB, Akers BM. Orgasm equality: scientific findings and societal implications. Curr Sex Health Rep. 2020;12(1): 24-32.

17. Andrejek N, Fetner T. The gender gap in orgasms: survey data from a mid-sized Canadian city. Int J Sex Health. 2019;31(1):26-35.

18. Labaka A, Goñi-Balentziaga $\mathrm{O}$, Lebeña A, Pérez-Tejada J. Biological sex differences in depression: a systematic review. Biological Research For Nursing. 2018;20(4):383-92. 
19. Jalnapurkar I, Allen M, Pigott T. Sex differences in anxiety disorders: a review. Journal of Psychiatry, Depression \& Anxiety. 2018;4(1):3-16.

20. Rubinow DR, Schmidt PJ. Sex differences and the neurobiology of affective disorders. Neuropsychopharmacology. 2019;44(1):111-28.

21. Laumann EO, Paik A, Rosen RC. Sexual dysfunction in the United States: Prevalence and predictors. JAMA: Journal of the American Medical Association. 1999;281(6):537-44.

22. Peixoto MM, Nobre P. Prevalence and sociodemographic predictors of sexual problems in Portugal: a population-based study with women aged 18 to 79 years. Journal of Sex \& Marital Therapy. 2015;41(2):169-80.

23. Heredia D, Rider GN. Intersectionality in sex therapy: opportunities for promoting sexual wellness among queer people of color. Curr Sex Health Rep. 2020;12(3):195-201.

24. Riley T, Sully E, Ahmed Z, Biddlecom A. Estimates of the Potential Impact of the COVID-19 Pandemic on sexual and reproductive health in low and middle-income countries. Int Perspect Sex Reprod Health. 2020;46:73-6.

25. Hall KS, Samari G, Garbers S, Casey SE, Diallo DD, Orcutt M, et al. Centring sexual and reproductive health and justice in the global COVID-19 response. Lancet. 2020;395(10231):1175-7.

26. Rosen R, et al. The Female Sexual Function Index (FSFI): a multidimensional self-report instrument for the assessment of female sexual function. Journal of sex \& marital therapy. 2000;26(2):191-208.

27. Ballester-Arnal, R., et al., "INSIDE" project on sexual health in Spain: sexual life during the lockdown caused by COVID-19. Sexuality Research and Social Policy, 2020.

28. Carvalho J, et al. The relationship between COVID-19 confinement, psychological adjustment, and sexual functioning, in a sample of Portuguese men and women. J Sex Med. in press.

29. Pascoal PM, Carvalho J, Raposo CF, Almeida J, Beato AF. The impact of COVID-19 on sexual health: a preliminary framework based on a qualitative study with clinical sexologists. Sexual Medicine. 2021;9(1):100299.

30. Karagöz MA, Gül A, Borg C, Erihan İB, Uslu M, Ezer M, et al. Influence of COVID-19 pandemic on sexuality: a cross-sectional study among couples in Turkey. Int J Impot Res. 2020.

31. Fuchs A, et al. Int J Environ Res Public Health. 2020:17(19).

32. Kaya Y, et al. Examination of the effect of COVID-19 on sexual dysfunction in women. Int J Clin Pract. 2020:e13923.

33. Schiavi MC, Spina V, Zullo MA, Colagiovanni V, Luffarelli P, Rago R, et al. Love in the time of COVID-19: sexual function and quality of life analysis during the social distancing measures in a group of italian reproductive-age women. J Sex Med. 2020;17(8):1407-13.

34. Omar SS, Dawood W, Eid N, Eldeeb D, Munir A, Arafat W. Psychological and sexual health during the COVID-19 pandemic in Egypt: are women suffering more? Sexual Medicine. 2021;9(1): 100295.

35. Cocci A, Giunti D, Tonioni C, Cacciamani G, Tellini R, Polloni G, et al. Love at the time of the Covid-19 pandemic: preliminary results of an online survey conducted during the quarantine in Italy. Int J Impot Res. 2020;32(5):556-7.

36. De Rose AF, et al. Sexuality during COVID lockdown: a crosssectional Italian study among hospital workers and their relatives. Int J Impot Res. 2021;33(1):131-6.

37. Gouvernet B, Bonierbale M. COVID-19 lockdown impact on cognitions and emotions experienced during sexual intercourse. Sexologies. 2021;30(1):e9-e21.

38. Gul, Z.B., Depression and sexual functions in epilepsy patients: comparison before and during the COVID-19 pandemic. Annales Médico-psychologiques, revue psychiatrique, 2021.

39. Daneshfar Z, Jahanian Sadatmahalleh S, Youseflu S, Bahri Khomami M, Kazemnejad A. Influential factors on quality of life in married Iranian women during the COVID-19 pandemic in 2020: a path analysis. BMC Womens Health. 2021;21(1):102.

40. Li G, Tang D, Song B, Wang C, Qunshan S, Xu C, et al. Impact of the COVID-19 pandemic on partner relationships and sexual and reproductive health: cross-sectional, online survey study. J Med Internet Res. 2020;22:e20961. https://doi.org/10.2196/20961.

41. Culha MG, Demir O, Sahin O, Altunrende F. Sexual attitudes of healthcare professionals during the COVID-19 outbreak. Int J Impot Res. 2021;33(1):102-9.

42. Yuksel B, Ozgor F. Effect of the COVID-19 pandemic on female sexual behavior. Int J Gynaecol Obstet. 2020;150(1):98-102.

43. Mollaioli D, Sansone A, Ciocca G, Limoncin E, Colonnello E, di Lorenzo G, et al. Benefits of sexual activity on psychological, relational, and sexual health during the COVID-19 breakout. J Sex Med. 2021;18(1):35-49.

44. Karsiyakali N, Sahin Y, Ates HA, Okucu E, Karabay E. Evaluation of the sexual functioning of individuals living in Turkey during the COVID-19 pandemic: an Internet-based nationwide survey study. Sexual Medicine. 2021;9(1):100279.

45. Li W, Li G, Xin C, Wang Y, Yang S. Challenges in the practice of sexual medicine in the time of COVID-19 in China. J Sex Med. 2020;17(7):1225-8

46. Feng Y-J, Fan YJ, Su ZZ, Li BB, Li B, Liu N, et al. Correlation of sexual behavior change, family function, and male-female intimacy among adults aged 18-44 years during COVID-19 epidemic. Sexual Medicine. 2021;9(1):100301.

47. Coombe, J., et al., Love during lockdown: findings from an online survey examining the impact of COVID-19 on the sexual health of people living in Australia. Sexually Transmitted Infections, 2020: p. sextrans-2020-054688.

48. Zattoni F, Gül M, Soligo M, Morlacco A, Motterle G, Collavino J, et al. The impact of COVID-19 pandemic on pornography habits: a global analysis of Google Trends. Int J Impot Res. 2020.

49. Wignall L, Portch E, McCormack M, Owens R, Cascalheira CJ, Attard-Johnson J, et al. Changes in sexual desire and behaviors among UK young adults during social lockdown due to COVID19. J Sex Res. 2021:1-10.

50. Cito G, Micelli E, Cocci A, Polloni G, Russo GI, Coccia ME, et al. The impact of the COVID-19 quarantine on sexual life in Italy. Urology. 2021;147:37-42.

51. Karakas LA, et al. Risk factors for sexual dysfunction in pregnant women during the COVID-19 pandemic. International journal of gynaecology and obstetrics: the official organ of the International Federation of Gynaecology and Obstetrics. 2021;152(2):226-30.

52. Mirzaei N, Jahanian Sadatmahalleh S, Bahri Khomami M, Moini A, Kazemnejad A. Sexual function, mental health, and quality of life under strain of COVID-19 pandemic in Iranian pregnant and lactating women: a comparative cross-sectional study. Health Qual Life Outcomes. 2021;19(1):66.

53. Lorentz MS, Chagas LB, Perez AV, da Silva Cassol PA, Vettorazzi $\mathrm{J}$, Lubianca JN. Correlation between depressive symptoms and sexual dysfunction in postpartum women during the COVID-19 pandemic. Eur J Obstet Gynecol Reprod Biol. 2021;258:162-7.

54. Panzeri M, Ferrucci R, Cozza A, Fontanesi L. Changes in sexuality and quality of couple relationship during the Covid-19 lockdown. Front Psychol. 2020;11.

55. Hidalgo DA, Dewitte M. Individual, relational, and sociocultural determinants of sexual function and sexual satisfaction in Ecuador. Sexual Medicine. 2021;9(2):100307.

56. Gillespie SM, Jones A, Uzieblo K, Garofalo C, Robinson E. Coping using sex during the coronavirus disease 2019 (COVID-19) outbreak in the United Kingdom. J Sex Med. 2021;18(1):50-62.

57. Lehmiller JJ, Garcia JR, Gesselman AN, Mark KP. Less sex, but more sexual diversity: changes in sexual behavior during the COVID-19 Coronavirus pandemic. Leis Sci. 2021;43(1-2):295304. 
58. Hille Z, Oezdemir UC, Beier KM, Hatzler L. The disruptive impact of the COVID-19 pandemic on sexual behavior of a Germanspeaking population. Sexologies. 2021;30(1):e23-33.

59. Micelli E, Cito G, Cocci A, Polloni G, Russo GI, Minervini A, et al. Desire for parenthood at the time of COVID-19 pandemic: an insight into the Italian situation. J Psychosom Obstet Gynecol. 2020;41(3):183-90.

60. Luetke M, Hensel D, Herbenick D, Rosenberg M. Romantic relationship conflict due to the COVID-19 pandemic and changes in intimate and sexual behaviors in a nationally representative sample of American adults. Journal of Sex \& Marital Therapy. 2020;46(8): 747-62.

61. Moghalu O, Hotaling J, Pastuszak A. Psychiatric comorbidities and sexual health. Curr Sex Health Rep. 2020;12(3):91-100.

62. Reisman Y. Are there any sex/gender differences in post-selective serotonin reuptake inhibitors (SSRI) sexual dysfunction (PSDD)? Curr Sex Health Rep. 2019;11(4):237-42.

63. Pascoal PM, Rosa PJ, Silva EP, Nobre PJ. Sexual beliefs and sexual functioning: the mediating role of cognitive distraction. Int J Sex Health. 2018;30(1):60-71.

64. Abdolmanafi A, Nobre P, Winter S, Tilley PJM, Jahromi RG. Culture and sexuality: cognitive-emotional determinants of sexual dissatisfaction among Iranian and New Zealand women. J Sex Med. 2018;15(5):687-97.

65. de Oliveira L, Carvalho J. The link between boredom and hypersexuality: a systematic review. J Sex Med. 2020;17(5):994-1004.

66. de Oliveira L, Carvalho J, Nobre P. A Systematic Review on Sexual Boredom. J Sex Med. 2021;18(3):565-81.

67. Presti G, et al. The dynamics of fear at the time of COVID-19: a contextual behavioral science perspective. Clinical Neuropsychiatry: Journal of Treatment Evaluation. 2020;17(2): 65-71.

68. Matthews SJ, et al. The battle against bedroom boredom: development and validation of a brief measure of sexual novelty in relationships. Can J Hum Sex. 2018;27(3):277-87.

69. Rosa MN, Matthews SA, Giuliano TA, Thomas KH, Swift BA, Mills MM. Encouraging erotic variety: identifying correlates of, and strategies for promoting, sexual novelty in romantic relationships. Personal Individ Differ. 2019;146:158-69.

70. de Oliveira L, Carvalho J, Nobre P. Perceptions of sexual boredom in a community sample. Journal of Sex \& Marital Therapy. 2020;47(3):224-37.

71. Daspe M-È, Vaillancourt-Morel MP, Lussier Y, Sabourin S, Ferron A. When pornography use feels out of control: the moderation effect of relationship and sexual satisfaction. Journal of Sex \& Marital Therapy. 2018;44(4):343-53.

72. Quinn-Nilas C. Relationship and sexual satisfaction: a developmental perspective on bidirectionality. J Soc Pers Relat. 2019;37(2): 624-46.

73. Caglar M, Mersin S, Ibrahimoglu O. Dyadic adjustment and sexual function in postmenopausal women. Annals of Medical Research. 2020;27(3):955-63.

74. Williamson HC. Early effects of the COVID-19 pandemic on relationship satisfaction and attributions. Psychol Sci. 2020;31(12): 1479-87.

75. Schmid, L., et al., Changes in employment and relationship satisfaction in times of the COVID-19 pandemic: evidence from the German family Panel. European Societies, 2021. 23(sup1): p. S743-S758.

76. Li Y, Samp JA. The impact of the COVID-19 pandemic on samesex couples' conflict avoidance, relational quality, and mental health. J Soc Pers Relat. 2021:02654075211006199.

77. Rosen R, et al. The International Index of Erectile Function (IIEF): A multidimensional scale for assessment of erectile dysfunction. Urology. 1997;49(6):822-30.
78. Guitelman J, et al. Effectiveness of a bibliotherapy intervention for young adult women's sexual functioning. Sex Relatsh Ther. 2019: $1-21$.

79. Cortoni F, Marshall WL. Sex as a coping strategy and its relationship to juvenile sexual history and intimacy in sexual offenders. Sexual Abuse: A Journal of Research and Treatment. 2001;13(1): $27-43$.

80. Nobre PJ, Pinto-Gouveia J. Sexual modes questionnaire: Measure to assess the interaction among cognitions, emotions, and sexual response. J Sex Res. 2003;40(4):368-82.

81. McGahuey A, et al. The Arizona Sexual Experience Scale (ASEX): reliability and validity. Journal of Sex \& Marital Therapy. 2000;26(1):25-40.

82. Fisher WA, White LA, Byrne D, Kelley K. Erotophobia-erotophilia as a dimension of personality. J Sex Res. 1988;25(1):123-51.

83. Muehlenhard, C.L. and D.M. Quackenbush, Sexual double standard scale, in Handbook of sexuality-related measures, C.M. Davis, W.L. Yarber, and L.D. Sandra 1998, Sage Publications: Thousand Oaks, CA p 186-188.

84. Nobre PJ, Pinto-Gouveia J, Gomes FA. Sexual dysfunctional beliefs questionnaire: an instrument to assess sexual dysfunctional beliefs as vulnerability factors to sexual problems. Sex Relatsh Ther. 2003;18(2):171-204.

85. Štulhofer A, Buško V, Brouillard P. Development and bicultural validation of the new sexual satisfaction scale. J Sex Res. 2010;47(4):257-68.

86. Penke L, Asendorpf JB. Beyond global sociosexual orientations: a more differentiated look at sociosexuality and its effects on courtship and romantic relationships. J Pers Soc Psychol. 2008;95(5): 1113-35.

87. Jacob L, Smith L, Butler L, Barnett Y, Grabovac I, McDermott D, et al. Challenges in the practice of sexual medicine in the time of COVID-19 in the United Kingdom. J Sex Med. 2020;17(7):122936.

88. Warshowsky H, Mosley DV, Mahar EA, Mintz L. Effectiveness of undergraduate human sexuality courses in enhancing women's sexual functioning. Sex Education. 2020;20(1):1-16.

89. Coban S. Gender and telework: work and family experiences of teleworking professional, middle class, married women with children during the Covid-19 pandemic in Turkey. Gend Work Organ. 2021.

90. Salas-Nicás S, Moncada S, Llorens C, Navarro A. Working conditions and health in Spain during the COVID-19 pandemic: minding the gap. Saf Sci. 2021;134:105064.

91. Pascoe, L., Negotiating HIV and pregnancy prevention and sexual pleasure amongst heterosexual men and women in South Africa. Culture, health \& sexuality, 2020: p. 1-16.

92. Carter A, Ford JV, Luetke M, Fu TC(J), Townes A, Hensel DJ, et al. "Fulfilling His Needs, Not Mine": Reasons for not talking about painful sex and associations with lack of pleasure in a nationally representative sample of women in the United States. J Sex Med. 2019;16(12):1953-65.

93. World Association for Sexual Health Declaration on sexual pleasure. 2019.

94. Joyce CRB, Zutshi DW, Hrubes V, Mason RM. Comparison of fixed interval and visual analogue scales for rating chronic pain. Eur J Clin Pharmacol. 1975;8(6):415-20.

95. Hudson, W.W., Index of Sexual Satisfaction, in Handbook of sexuality-related measures, C. Davis, et al 1998, Sage Publications: Thousand Oaks, CA p 512-513.

96. Taylor JF, Rosen RC, Leiblum SR. Self-report assessment of female sexual function: psychometric evaluation of the brief index of sexual functioning for women. Arch Sex Behav. 1994;23(6):62743. 
97. Panzeri M, Raoli V. Il Brief Index of Sexual Functioning for Men (BISF-M): validazione su un campione italiano. Rivista di sessuologia clinica. 2010;1:41-68.

98. Spector IP, Carey MP, Steinberg L. The sexual desire inventory: development, factor structure, and evidence of reliability. Journal of sex \& marital therapy. 1996;22(3):175-90.

99. DeRogatis L, Clayton A, Lewis-D'Agostino D, Wunderlich G, Fu Y. Validation of the female sexual distress scale-revised for assessing distress in women with hypoactive sexual desire disorder. J Sex Med. 2008;5(2):357-64.

Publisher's Note Springer Nature remains neutral with regard to jurisdictional claims in published maps and institutional affiliations. 